All treatment was immediately stopped, extra assistance was called and the emergency trolley was deployed. The patient was continually monitored and reassured. We administered chloropheniramine $20 \mathrm{mg}$ and closely monitored him. The medical history was rechecked and he reported no known allergies or history of any other similar swellings. The medication list comprised of Metformin, Amlodipine, Atenolol, Ramipril and Allopurinol. Apart from this the medical history was unremarkable.

The patient was taken to ActE where he was kept on corticosteroids for a further two hours as the swelling started to subside. He was diagnosed as having angiodema secondary to ACE inhibitors. A report was immediately sent back to his general medical practitioner, asking them to change his ACE inhibitor medication. Following on from this there have been no further swellings.

Angiodema secondary to ACE inhibitors is a serious complication and some deaths have even been reported. This type of angiodema is becoming increasingly common for two reasons. The first being that ACE inhibitors are incredibly successful in the treatment of hypertension and congestive heart failure, and secondly due to the rise of life expectancy in Western societies, which has led to more patients with hypertension and congestive heart failure that have been prescribed these drugs. The swelling can be severe and therefore these drugs must always be considered in the medical history, as well as when investigating swellings around the lips, mouth and tongue as quite often they can mimic anaphylaxis type reactions or food allergies.

The angiotensin converting enzyme metabolises bradykinin, a potent vasodilating substance and converts angiotensin I to angiotensin II. Angiotensin II causes vasoconstriction and increases smooth muscle hypertrophy, both of which can lead to an increase in blood pressure. The ACE inhibitor therefore prevents conversion of angiotensin I to angiotensin II thereby lowering arteriolar resistance and increasing venous capacity. This causes extravasation of fluid into the subcutaneous tissues, which produces angiodema. For an unknown reason people of
Afro-Caribbean origin are more at risk.

The acute management in these cases involves securing the patency of the upper airway. The next step, depending on the severity, can be the use of medications such as antihistamines, corticosteroids and if needed, adrenaline. In the secondary care setting intubation and surgical intervention may also be required in extreme cases. Long-term management includes changing medication.

Angiodema of the head and neck is potentially a life threatening condition that could quite easily present to the general dental practitioner and needs urgent attention and treatment.

P. Raval

London

DOI: $10.1038 /$ sj.bdj.2012.275

\section{THIRD MOLAR VISION}

Sir, as a dentally qualified maxillofacial SHO I was somewhat bemused when a patient calmly asked if I could reassure her about something. 'My mum has told me when your wisdom teeth are pulled out your eyes can get pulled back permanently because of all the blood vessels and nerves being connected, is this true?' Racking my brains of my first year anatomy I felt confident to reassure the patient to the contrary. I wonder if this is a common concern or an urban rumour?

R. Carr

Bristol

DOI: 10.1038/sj.bdj.2012.276

\section{WAGGING TONGUES}

Sir, your correspondents S. Surendran, E. Thomas and S. Asokan describe a hypermobile tongue in a young patient (BDJ 2012; 212: 55-56).

In a paper that I wrote 42 years ago in your esteemed journal, I described the same phenomenon which I had thought at the time was rare and remarkable (Becker A. Acquired extraordinary movements of a normal tongue. Br Dent $J$ 1970; 128: 396-397). The article generated some lively responses to the editor and a similar case was presented in a lecture given by Prof. William Proffit of the University of North Carolina, USA, in Jerusalem two years ago. 